\title{
Correction to: Effects of Growth Hormone Supplementation on Poor Ovarian Responders in Assisted Reproductive Technology: a Systematic Review and Meta-Analysis
}

\author{
Fen-Ting Liu ${ }^{1} \cdot$ Kai-Lun $\mathrm{Hu}^{2} \cdot$ Rong $\mathrm{Li}^{1}$ \\ Published online: 5 January 2021 \\ (C) Society for Reproductive Investigation 2020
}

\section{Correction to: Reprod. Sci.}

https://doi.org/10.1007/s43032-020-00298-0

This article was updated to correct the labeling of Figs. 3, 4, 5, $6,7,8$, and 9 , as well as the labeling of Online Resources 3, 4, $5,6,7,8$, and 9 .

Publisher's Note Springer Nature remains neutral with regard to jurisdictional claims in published maps and institutional affiliations.

The online version of the original article can be found at https://doi.org/ 10.1007/s43032-020-00298-0

\section{Rong Li \\ roseli001@sina.com \\ Fen-Ting Liu \\ 624603036@qq.com}

Kai-Lun $\mathrm{Hu}$

hukailun@bjmu.edu.cn

$1 \quad$ Beijing Key Laboratory of Reproductive Endocrinology and Assisted Reproductive Technology and Key Laboratory of Assisted Reproduction (Peking University), Ministry of Education, National Clinical Research Center for Obstetrics and Gynecology, Center for Reproductive Medicine, Department of Obstetrics and Gynecology, Peking University Third Hospital, Beijing 100191, China

2 Women's Hospital, School of Medicine, Zhejiang University, Hangzhou 310006, China 